\title{
Nanoparticles as Drilling Fluids Rheological Properties Modifiers
}

\author{
Majid S Al Ruqeishi*, Younis Al Salmi and Tariq Mohiuddin \\ Department of Physics, Sultan Qaboos University, Oman \\ *Corresponding author: Majid S Al Ruqeishi, Department of Physics, College of Science, Sultan Qaboos University, Oman.
}

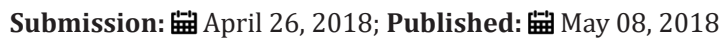

\begin{abstract}
Drilling for water, oil, or even gas using water-based drilling fluids faces major challenges. These are mainly related to drilling fluid leakage into the surrounding formation, water loss into fractures, and the reduction of fluid density or/and viscosity through the drilling circulation process. Nanoadditives with high surface to volume ratio of carbon nanoparticles (CNP), 50nm, and $\mathrm{ZnO}$ nanowires provide significant control of drilling fluid rheological properties. CNP additives were found to maintain the homogeneity of the drilling fluid components for a longer time and delay fluid sagging effect. Drilling fluid densities were enhanced by a factor of 4-10\% after addition of CNP or ZnO nanowires to the untreated drilling fluid by 1-3 wt. \%. Progressively, when 1, 2 and $3 \mathrm{~g}$ of CNP was added to the drilling fluid, the resultant filtrate water volume was reduced by 7, 4.8 and $4 \mathrm{~mL}$ respectively. The maximum water loss reduction measured was about $50 \%$ of the total fluid loss. Additionally, about a $24 \%$ increase in the drilling fluid viscosity was achieved when $2 \mathrm{~g}$ of $\mathrm{ZnO}$ nanowires were added.
\end{abstract}

\section{Introduction}

The drilling operation is the first stage in tapping underground oil, gas, and water. The proper development of this operation plays a major role in increasing productivity. Drilling fluid, mud, is pivotal in achieving this objective. Drilling fluids can be of many types; water-based, oil-based, synthetic-based fluids, and pneumatic or air fluids are a few commonly used in drilling. Water-based fluids are the most common. They are utilized to drill approximately $80 \%$ of all wells and are more economical compared to oil or synthetic-based fluids [1,2]. Drilling fluids have various functions during the drilling operation. These including: transport of cuttings to the surface, maintaining the wellbore pressure and stability, lubrication and cooling of the drill bit and isolation of formation fluids and gases by forming a filter cake around the borehole. Most troublesome drilling issues are directly or indirectly triggered by fluid related problems and the most recurring are loss of drilling fluid and wellbore instability. Drilling fluid circulation loss, which is defined as the gradual or accidental loss of drilling fluid to formation voids is one of the most well-known drilling problems. This leads to higher costs due to increase in the time required to reach the target depth, loss of pressure control, increased safety concerns on the rigs, contamination of waterbeds as well as several other consequences [3]. A large effort has been put into the development of new Lost Circulation Materials (LCMs) and technologies to plug the openings in the wellbores, with various levels of success. The key to experience a "fluid loss free" drilling operation lies within the ability to build a firm and high strength plug over the fractures and other types of "thief zones" to maintain the fluid level in the borehole $[4,5]$. LCMs with diameters in the range of $0.1-100 \mu \mathrm{m}$ could play an important role when the fluid loss occurs in $0.1 \mu \mathrm{m}$ $\mathrm{l} \mathrm{mm}$ porous formations. However, the size of pore openings in formations such as shale,lead to lossesin the range of $10 \mathrm{~nm}$ to $0.1 \mu \mathrm{m}$ and here LCM's are not very effective [6]. Nanoparticles can be described as solid particles or particulate dispersion in the size range of 1 to $100 \mathrm{~nm}$. Amanullah \& Al Tahini [7] define nanofluid as the fluid used in oil and gas drilling and exploitation which contains at least one nanoscale additive. As shale formations have small pores, the prevention of the fluid from penetrating into this formation is the main application of the nanoparticles in the drilling fluids. The presence of nanoparticles contributes to the sealing of the micro cracks in the shale and hence the filter cake becomes dense, thinner and impermeable. Forming such a filter cake reduces the fluid loss and stabilizes the well [8-11]. Salem Ragab \& Noah [12] used nano-sized silica drilling fluids for the reduction of formation damage and fluid loss, thereby providing a smooth drilling operation.

William et al. [13] investigated the effect of $\mathrm{CuO}$ and $\mathrm{ZnO}$ nanofluids combined with xan than gum on the thermal, electrical and rheological properties of the water-based drilling fluids. Results showed that the increased concentration of nanoparticles enhances electrical and thermal properties and improves rheological stability when using the nanofluid-enhanced waterbased drilling mud. Moreover, these results are the same as those 
of additives such as carbon black [14], palygorskite nanoparticles [15] and multiwall carbon nanotube [16]. Additionally, natural polymer nanoparticles like polyanionic cellulose polymer [17] and carboxymethyl cellulose [18,19] (CMC) nanoparticles [20] have been reported to reduce the amount of fluid loss and mud cake thickness. Therefore, the created mud cake is uniform and rheological properties are improved when nanoparticles are used. In addition, tiny nanoparticles with high surface to volume ratio can enhance various characteristics and control over fluid loss behavior simultaneously. In this article, fluid loss, density and viscosity tests on water-based drilling fluid from Wadi Laithm oil field, located in southern Sultanate of Oman, were investigated before and after adding carbon nanoparticles and $\mathrm{ZnO}$ nanostructures. Rheological evaluations like drilling mud's filtration loss properties were done by Filter Press API (LPLT) from Fan. The viscosity was measured by a dynamic viscometer expert series from fungi lab and fluid density measured by Anton Paar DMA 5000. The nano-additives were characterized by scanning electron microscopy (SEM) from JEOL, JSM-6510LA, equipped with JED-2300T energy-dispersive X-ray spectroscopy (EDX), high-resolution transmission electron microscope HRTEM (JEOL, JEM-2010).

\section{Experimental Setup}

Water base mud (WBM) from the Wadi Laitham oil field, was obtained from Abraj Energy Services Company, Sultanate of Oman. WBM materials brought from Baroid- Halliburton Company and the materials concentrations for one barrel of water, $0.16 \mathrm{~m} 3$, are illustrated in Table 1. Each mass measured in pounds $(1 \mathrm{lb}=0.453 \mathrm{~kg})$. Then four samples each $600 \mathrm{ml}$ of the drilling fluids were utilized to do the rheological tests. Controlled nano-additives masses were added to the drilling fluid samples to investigate any modifications or changes occur in the drilling fluid rheological properties. The nano-additives are carbon nanoparticles (D and L, 50-250nm $\times$ $0.5-5 \mu \mathrm{m}$, purity $>99 \%$, purchased from Sigma Aldrich) and in house grown $\mathrm{ZnO}$ nanowires by chemical vapor deposition method.
Table 1: Drilling fluid additives as received from BaroidHalliburton Company.

\begin{tabular}{|c|c|}
\hline Additive Material & Concentration Lb/Bbl \\
\hline Bentonite & 15 \\
\hline $\begin{array}{c}\text { EZ MUD (partially hydrolyzed } \\
\text { polyacrylamide) }\end{array}$ & 1 \\
\hline PAC RE (Poly Anionic Cellulose) & 2.5 \\
\hline Magnesium Oxide (Mg0) & 0.5 \\
\hline Soda ash $\left(\mathrm{Na}_{2} \mathrm{CO}_{3}\right)$ & 0.25 \\
\hline SALT $(\mathrm{NaCl})$ & 33 \\
\hline
\end{tabular}

\section{ZnO nanowires synthesis process}

In this process, we used a tube in tube chemical vapor deposition (CVD) system to produce large scale production of ZnO nanowires. Firstly, powders from Sigma Aldrich of graphite $(99.99 \%,<45 \mu \mathrm{m})$ and $\mathrm{ZnO}(99.9 \%,<5 \mu \mathrm{m})$, with mass ratio of (1:1) were mixed and grained well. Then an amount of $20 \mathrm{~g}$ of the mixture was added each time into a combustion boat and utilized as source material. The source material was loaded into a $3.8 \mathrm{~cm}$-inner diameter quartz tube (large tube), which was placed at the center of a $45 \mathrm{~cm}$ long horizontal tube furnace as shown in Figure 1. Then, another small quartz tube $(\mathrm{D}=2.6 \mathrm{~cm}$ and $\mathrm{L}=12 \mathrm{~cm})$ was loaded inside the horizontal quartz tube to work to increase the growth possible locations. The inner sides of both the large and small quartz tubes are the locations expected to see large-scale growth of $\mathrm{ZnO}$ nanowires. The horizontal quartz tube was connected to an argon (99.999\% purity) gas supply and a flow rate control system at one end while the other end was kept open as it is shown in Figure 1. The Ar gas was then flushed inside the quartz tube to get rid of all other gases and kept at a steady $10 \mathrm{sccm}$. The furnace was then switched on and the temperature was raised up to $(1000 \pm 15$ ${ }^{\circ} \mathrm{C}$ ) at a heating rate of $1.2^{\circ} \mathrm{C} / \mathrm{s}$.

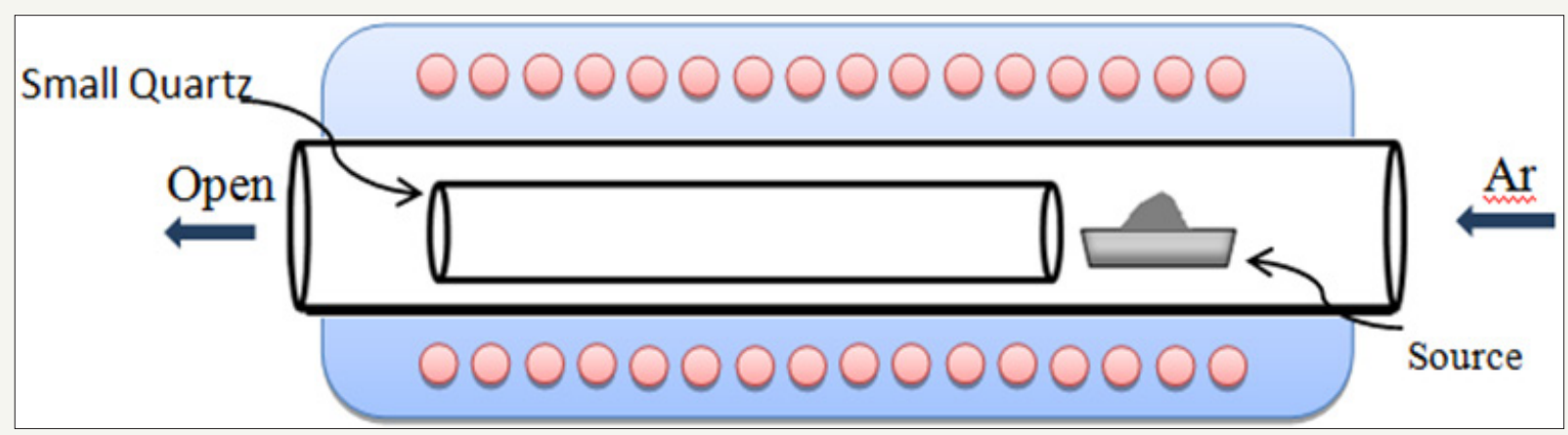

Figure 1: Tube in tube CVD growth process for large-scale production of $\mathrm{ZnO}$ nanowires.

The temperature is constant in the middle area of the furnace but gradually decreases near the edges. After the source material had completely evaporated, the furnace was turned off and let to cool down to room temperature under same the Ar flow rate. The inner side of the short quartz tube was covered with thin whitegray color layerat locations near to the source material. Then newly formed thin layer was scratched out from the tubes sides. Finally, the nano structures in powder form were taken for further analysis and characterization.

\section{Drilling fluid preparation}

First, four samples of $600 \mathrm{ml}$ drilling fluids were prepared in beakers. The 1, 2 and 3 grams of both carbon nanoparticles (CNp), $50 \mathrm{~nm}$ in size, and $\mathrm{ZnO}$ nanowires were added respectively to the 
mud. Lastly a reference sample was also used. Each sample was then mixed using a blender for five minutes.

\section{Results and Discussions}

\section{Characterization of Nanomaterials}

Carbon nanoparticles ( $\mathrm{CNp}$ ) and $\mathrm{ZnO}$ nanowires were utilized as nano-additives to enhance the WBM's rheological properties. CNp with diameters between $50-250 \mathrm{~nm}$ and lengths between 0.5 -
$5 \mu \mathrm{m}$, purity $>99 \%$, purchased from Sigma Aldrich. As it is shown in Figure 2(a), these nanoparticles are semi-spherical in shape and diverge in size. The other nano-additives, $\mathrm{ZnO}$ nanowires, were grown by CVD at $1000{ }^{\circ} \mathrm{C}$ under 150 -sccmAr gas flow rate. Figure 2(b) illustrates these nanowires with randomly distributed with an average diameter and length of $74 \pm 16 \mathrm{~nm}$ and $1.3 \pm 0.10 \mu \mathrm{m}$ respectively. Figure 2(c) shows the EDX spectrum taken for Figure 2(b), which indicates the existence of zinc, oxygen and silicon elements in the nanowires.

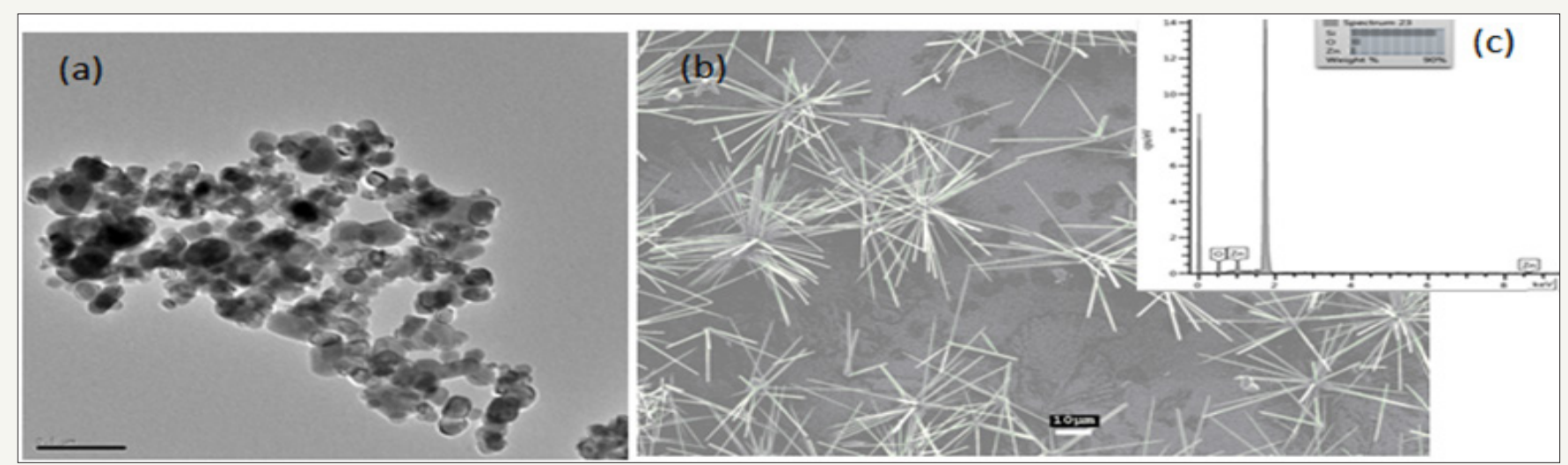

Figure 2(a): These nanoparticles are semi-spherical in shape and diverge in size. The other nano-additives, ZnO nanowires, were grown by CVD at $1000{ }^{\circ} \mathrm{C}$ under $150-$ sccmAr gas flow rate.

Figure 2(b): Illustrates these nanowires with randomly distributed with an average diameter and length of $74 \pm 16 \mathrm{~nm}$ and $1.3 \pm 0.10 \mu \mathrm{m}$ respectively.

Figure 2(c): Shows the EDX spectrum taken for Figure 2(b), which indicates the existence of zinc, oxygen and silicon elements in the nanowires.

\section{Sagging effect and drilling fluid density}

These two different nanomaterials were chosen upon differences in their size and shape. Most of the atoms in the smaller size particle are located at its surface more than the bulk. Moreover, this is important to increase chemical reactivity between nanoparticles and its surrounding aqueous medium. In addition, nanoparticle shape, sphere or wire, plays a vital role to maintain better mixing process as well as long chemical effect like drilling fluids rheological properties, density, water loss and viscosity. However, before revealing the results of the nano-additives effects on these properties when mixed with drilling fluid, another phenomenon called sagging effect occurred within the drilling fluid when stored for long time. Sagging effect one of major drawbacks facing the drilling fluid industry especially in many directional drilling processes. The term "sag" explains the separation of two liquids phases due to concentration of weighting material used to increase the density of drilling fluids. Sagging effect results are shown in Figure 3 for both drilling fluid without nano-additives and with additional of carbon nanoparticles (50nm in size) after three weeks' time. It was clear that the treated fluid still mixed after three weeks and was no indication of phase separation as shown in Figure 3. Bentonite works to suspend all fluid components by attracting them electrically, charge to charge binding. When carbon nanoparticles ( $\mathrm{CNp}$ ) with high charged surface to volume ratio, are added and mixed more attraction forces will keep all components suspended to the polar water.

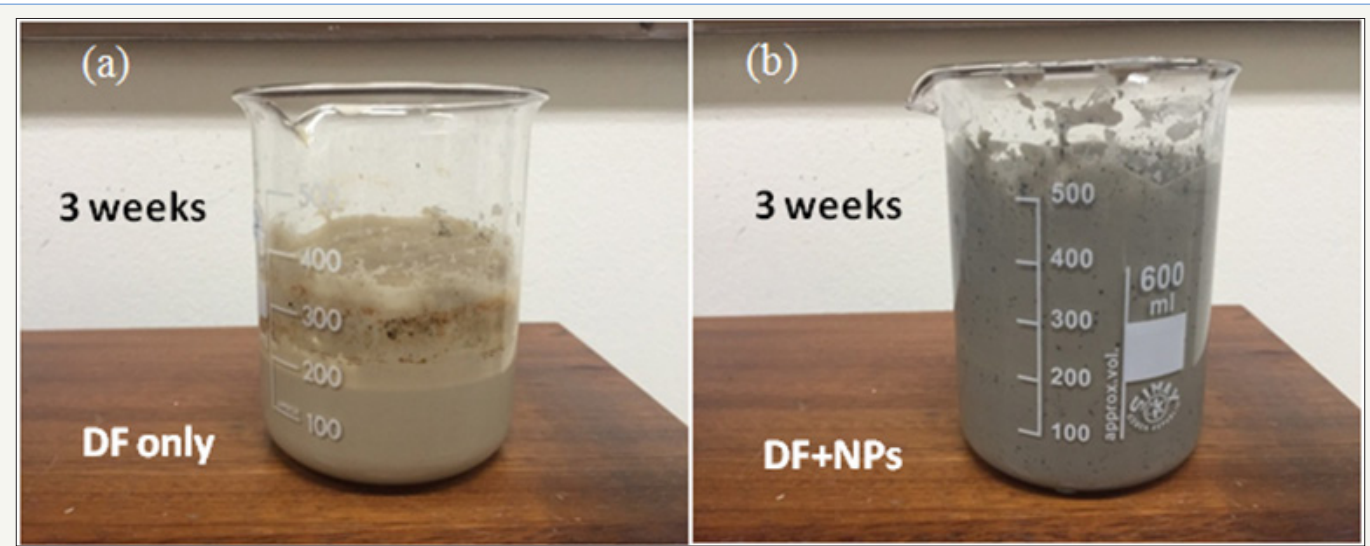

Figure 3: Sagging effect of prepared drilling fluid (a) without any additives and (b) with black carbon nanoparticles (50nm). 


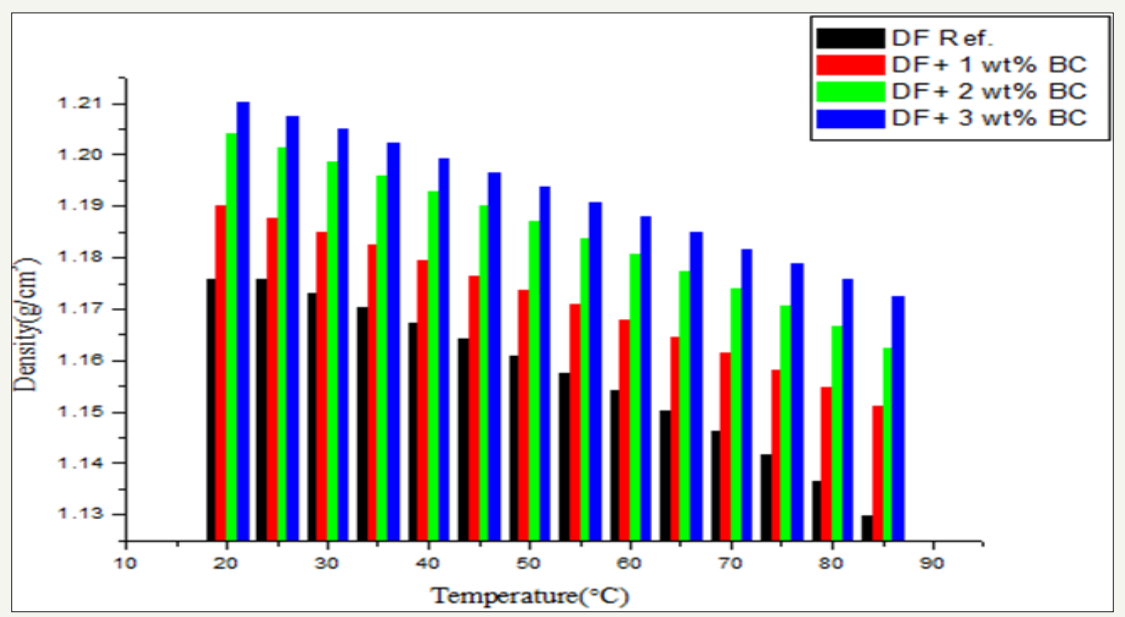

Figure 4: Drilling fluid densities without additives (DF) and after adding 1, 2 and 3 wt. \% of carbon nanoparticles (CNp).

Table 2: The measurements of drilling fluid densities after addition of carbon nanoparticles (CNp) and $\mathrm{ZnO}$ nanowires to the untreated drilling fluid at specific temperature.

\begin{tabular}{|c|c|c|c|c|c|}
\hline \multirow{2}{*}{ Drilling fluid } & \multirow{2}{*}{ NPs Used } & \multirow{2}{*}{ Temperature $\left({ }^{\circ} \mathrm{C}\right)$} & \multicolumn{2}{|c|}{ Density $\left(\mathrm{g} / \mathrm{cm}^{3}\right)$} & \multirow{2}{*}{ Increment \% } \\
\hline & & & $\mathrm{DF}+\mathrm{NPs}$ & DF & \\
\hline \multirow{8}{*}{ WBM } & \multirow{4}{*}{$\begin{array}{l}\text { Black carbon particles } \\
\qquad(3 \mathrm{w} \%)\end{array}$} & 25 & $1.22 \pm 0.5$ & $1.17 \pm 0.5$ & 4.3 \\
\hline & & 35 & $1.21 \pm 0.5$ & $1.16 \pm 0.5$ & 4.3 \\
\hline & & 65 & $1.19 \pm 0.5$ & $1.15 \pm 0.5$ & 3.5 \\
\hline & & 85 & $1.17 \pm 0.5$ & $1.13 \pm 0.5$ & 3.5 \\
\hline & \multirow{4}{*}{$\mathrm{ZnO}$ nanowires (3w \%) } & 25 & $1.27 \pm 0.5$ & $1.15 \pm 0.5$ & 10.4 \\
\hline & & 35 & $1.25 \pm 0.5$ & $1.14 \pm 0.5$ & 9.6 \\
\hline & & 65 & $1.22 \pm 0.5$ & $1.12 \pm 0.5$ & 8.9 \\
\hline & & 85 & $1.18 \pm 0.5$ & $1.10 \pm 0.5$ & 7.3 \\
\hline
\end{tabular}

On the other hand, to control the stability of wellbore's hydrostatic pressure, the fluid density should be well maintained. Fluid densities were measured by using temperature-based dosimeter. Drilling fluid densities were taken at $20-85{ }^{\circ} \mathrm{C}$ temperatures before and after addition of carbon nanoparticles (CNp), as plotted in Figure 4.

As the temperature increases fluid becomes less dense, but

when amounts of 1, 2 and $3 \mathrm{wt}$.\% of carbon nanoparticles is added to the drilling fluid respectively, the reduction of density rate become small, see Figure 4. Additionally, the fluid density after adding $3 \mathrm{wt}$. $\%$ of $\mathrm{CNp}$ at $85^{\circ} \mathrm{C}$ exceeded that of the untreated or reference fluid at temperature of $20{ }^{\circ} \mathrm{C}$. To understand the effect of $\mathrm{CNp}$ additives in the overall fluid densities measurements at each temperature, Table 2 shows fluid density increment percentage after the addition of 3wt. \% of $\mathrm{CNp}$ and $\mathrm{ZnO}$ nanowires each trail.

\section{Effect of nano-additives in drilling fluid water lossproperty}

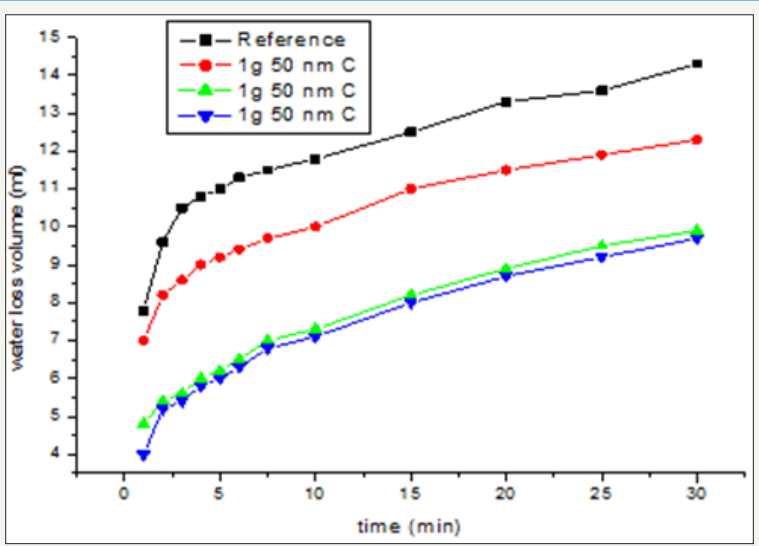

Figure 5: Water loss volume tests for drilling fluid before and after addition of carbon nanoparticles (CNp) of 1,2 and $3 \mathrm{~g}$ under pressure of $100 \mathrm{~Pa}$ at different share. 
Table 3: Water loses tests before and after addition of carbon nanoparticles $(\mathrm{CNp})$ at pressure of $100 \mathrm{~Pa}$ at different share time.

\begin{tabular}{|c|c|c|c|c|}
\hline Time(min) & Reference Mud (mL) & Mud+CNp (1) (mL) & Mud+CNp (2g) (mL) & Mud+CNp (3g) (mL) \\
\hline 1 & 7.8 & 7 & 4.8 & 4 \\
\hline 2 & 9.6 & 8.2 & 5.4 & 5.2 \\
\hline 3 & 10.5 & 8.6 & 5.6 & 5.4 \\
\hline 4 & 10.8 & 9 & 6 & 6 \\
\hline 5 & 11 & 9.2 & 6.2 & 6.3 \\
\hline 6 & 11.3 & 9.4 & 7 & 6.8 \\
\hline 7.5 & 11.5 & 9.7 & 7.3 & 7.1 \\
\hline 10 & 11.8 & 10 & 8.2 & 8 \\
\hline 15 & 12.5 & 11 & 8.9 & 8.7 \\
\hline 20 & 13.3 & 11.5 & 9.5 & 9.2 \\
\hline 30 & 13.6 & 11.9 & 12.3 & \\
\hline
\end{tabular}

A conventional drilling fluid loss test was conducting for 1-30 minutes share time. Additives of 1,2 and $3 \mathrm{~g}$ of carbon nanoparticles (CNp) in $600 \mathrm{ml}$ of WBM were used in order to check any differences in the mud filtration rate or water loss, see Table 3. In Figure 5 API filtrate loss measurements taken at different additives concentrations with different share rate. It is clearly show that with more addition of $\mathrm{CNp}$, large reduction in the filtrate volume is attainable. Started without nano-additives in the sample, filtrate volume is high at around $7.8 \mathrm{~mL}$ at one minutes share rate. Then addition of 1 and $2 \mathrm{~g}$ of $\mathrm{CNp}$, filtrate volume being reduced to about 7 and $4.8 \mathrm{~mL}$ respectively. Moreover, by adding $3 \mathrm{~g}$ of $\mathrm{CNp}$ the filtrate reaches its lowest volume of $4 \mathrm{~mL}$ at smallest share rate. The enhancement of drilling fluid density and lower its water loss will keep drilling fluid to cool down and lubricate the hot drilling bit while drilling and it will make less water to be lost within the drilled well surrounding formations.

\section{Effect of nano-additives in drilling fluid viscosity}

The viscosity of WBM was measured by using the dynamic viscometer and water bath with temperatures of $(25,45,65,85$ ${ }^{\circ} \mathrm{C}$ ) by increment of $5{ }^{\circ} \mathrm{C}$ heating rate each time at $50,100,150$, 200 rotation per minute (RPM). As the drilling fluid temperature increases less viscos it becomes, but this affect increases when CNp were added at different masses. In Table 4, when temperature and RBM are setup at $25{ }^{\circ} \mathrm{C}$ and 50 respectively, the drilling fluids viscosity is increases by $\sim 18 \%$ when only $1 \mathrm{~g}$ of $\mathrm{CNp}$ is added to $600 \mathrm{~mL}$ of the original drilling fluid. In addition, about $24 \%$ viscosity increment was measured when $2 \mathrm{~g}$ of $\mathrm{ZnO}$ nanowires were added in the same conditions, as revealed in Table 4. All viscosity measurements before and after adding $\mathrm{CNp}$ in all three conditions, the temperature value, the RBM and CNp masses are plotted in Figure 6.
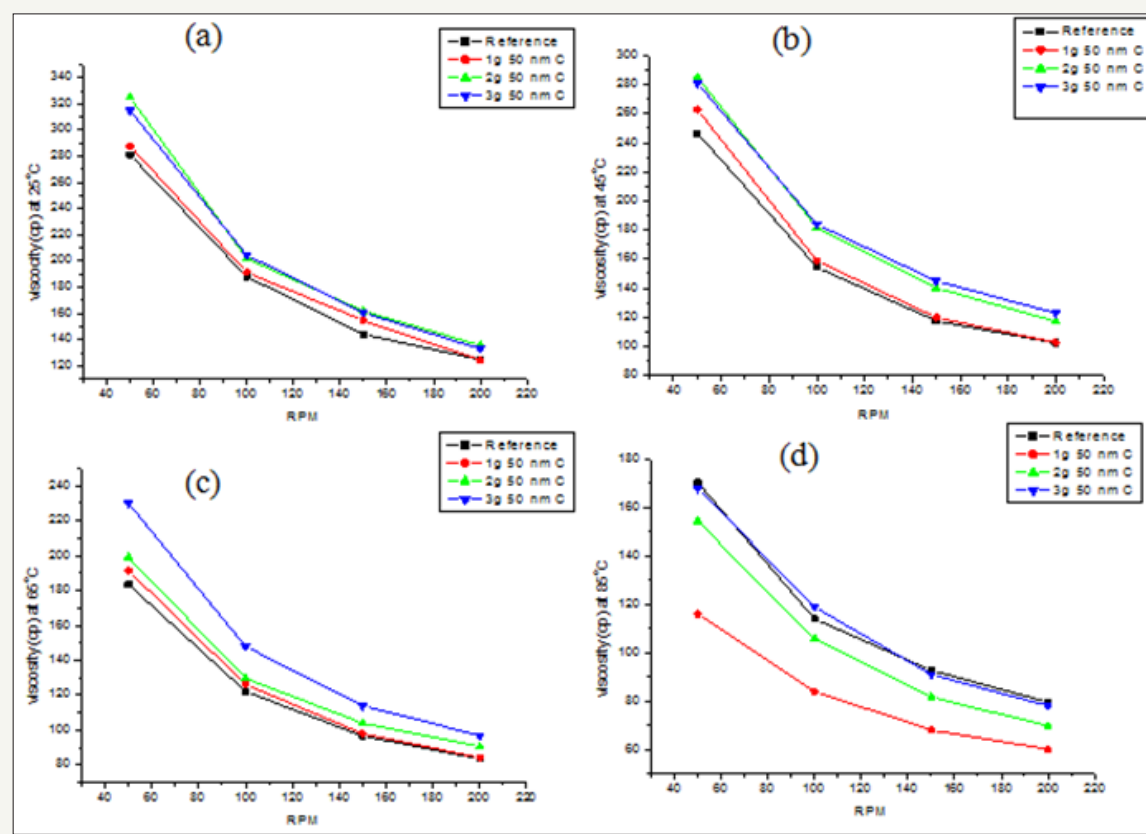

Figure 6: Drilling fluid viscosities before and after addition of 1,2 and $3 \mathrm{~g}$ of carbon nanoparticles $(\mathrm{CNp})$ underat $50,100,150$, 200RPM respectively. 
Table 4: Drilling fluids viscosities before and after addition of carbon nanoparticles (CNp) or ZnO nanoparticles at different temperatures and different share time.

\begin{tabular}{|c|c|c|c|c|c|}
\hline \multirow{2}{*}{ Drilling Fluid } & \multirow{2}{*}{ NPs Used } & \multirow{2}{*}{ RPM } & \multicolumn{2}{|c|}{ Viscosity (cp) } & \multirow{2}{*}{ Increment \% } \\
\hline & & & DF & NPs & \\
\hline \multirow{3}{*}{ WBM } & \multirow{3}{*}{$\mathrm{CNp}$} & 50 & $280 \pm 8$ & $330 \pm 8$ & 17.9 \\
\hline & & 100 & $190 \pm 8$ & $210 \pm 8$ & 10.5 \\
\hline & & 150 & $140 \pm 8$ & $160 \pm 8$ & 14.3 \\
\hline \multirow{3}{*}{ WBM } & \multirow{3}{*}{$\begin{array}{l}\mathrm{ZnO} \\
\mathrm{NW}\end{array}$} & 50 & $270 \pm 8$ & $324 \pm 8$ & 20 \\
\hline & & 100 & $170 \pm 8$ & $210 \pm 8$ & 24 \\
\hline & & 150 & $140 \pm 8$ & $170 \pm 8$ & 21 \\
\hline
\end{tabular}

ZnO nanowires as viscosifier additives found to be better than CNp when added with same amount, and this may be due to the nanowire shape with large surface to volume ratio. Controlling viscosity in drilling fluids is important to remove heavy cuttings and to control the fluid gel strength, results not shown in this study. Especially, at higher temperatures drilling fluid viscosity needs to maintain instantly. However, to get a very homogenate solution the nano-additives should be mix properly.

\section{Conclusion}

Nano-additives of carbon nanoparticles and/or in-house prepared $\mathrm{ZnO}$ nanowires were utilized to enhance the drilling fluid properties. A carbon nanoparticles additive succeeds to hinder the drilling fluid from the sagging effect for more than three weeks in time. Drilling fluid densities and viscosities was increased by the addition of 1-3wt. \% from carbon nanoparticles and/or $\mathrm{ZnO}$ nanowires. Nanowires additives increase the drilling fluid densities two times more than the spherical carbon nanoparticles. In addition, drilling fluid water loss is reduced significantly after the addition of a small fraction of carbon nanoparticles, which is important to lubricate the drilling bit and controlling the fluid viscosity. In future, different shapes, sizes and types of nano-additives will be utilized for oil and water based drilling fluid's performance enhancement.

\section{References}

1. World Oil (2004) Drilling, completion and work over fluids. World Oil 225 (6).

2. Berthezene N, Hemptinne J, Audibert A, Argillier J (1999) Methane solubility in synthetic oil-based drilling muds. J Petrol Sci Eng 23(2): 7181.

3. Oilfield Market Report (2004) Spears \& Assoc Inc. Tulsa, Oklahoma.

4. Chilingarian GV, Vorabutr P (1983) Drilling and Drilling Fluids. ( $\left.{ }^{\text {nd }} e d n\right)$, Elsevier, Amsterdam, Netherlands.

5. Adewumi MA, Tian S (1993) Multiphase hydrodynamic analysis of pneumatic transportation of drill cuttings in air drilling. Powder Technol 75(2): 133-144.

6. Husein M, Zakaria M, Hareland G (2013) Novel nanoparticle-containing drilling fluids to mitigate fluid loss. World Intellectual Property.

7. Amanullah Md, Al Tahini MA (2009) Nano-technology-its significance in smart fluid development for oil and gas field application. SPE Saudi Arabia Section Technical Symposium, Al-Khobar, Saudi Arabia.

8. Amanullah Md, Al Arfaj KM, Al Abdullatif Z (2011) Preliminary test results of nano based drilling fluids for oil and gas field application. Society of Petroleum Engineers, pp. 1-9.

9. Riley M, Young S, Stamatakis E, Guo Q, Ji L, et al. (2012) Wellbore stability in unconventional shale-the design of a nano-particle fluid. SPE Oil and Gas India Conference and Exhibition, Mumbai, India.

10. Rugang Y, Guancheng J, Wei L, Tianqing D, Hongxia Z (2014) Effect of water based drilling fluid components on filter cake structure. Powder Technol 262: 51-61.

11. Li G, Zhang J, Zhao H, Hou Y (2012) Nanotechnology to improve sealing ability of drilling fluids for shale with microcracks during drilling. SPE International Oilfield Nanotechnology Conference, Noordwijk, Netherlands.

12. Salem Ragab AM, Noah A (2014) Reduction of formation damage and fluid loss using nano-sized silica drilling fluids. Pet Technol Dev J 2: 7588.

13. William JKM, Ponmani S, Samuel R, Nagarajan R, Sangwai JS (2014) Effect of $\mathrm{CuO}$ and $\mathrm{ZnO}$ nanofluids in xanthan gum on thermal, electrical and high pressure rheology of water-based drilling fluids. J Petrol Sci Eng 117: 15-27.

14. Mirzaei Paiaman A, Al Anazi BD (2009) Feasibility of decreasing pipe sticking probability using nanoparticles, NAFTA 60(12): 645-647.

15. Abdo J, Haneef MD (2013) Clay nanoparticles modified drilling fluids for drilling of deep hydrocarbon wells. Appl Clay Sci 86: 76-82.

16. Sedaghatzadeh M, Khodadadi AA, Tahmasebi Birgani MR (2012) An improvement in thermal and rheological properties of water-based drilling fluids using multiwallcarbon nanotube (MWCNT). Iran J Oil Gas Sci Technol 1(1): 55-65.

17. Fereydouni M, Sabbaghi S, Saboori R, Zeinali S (2012) Effect of polyanionic cellulose polymer nanoparticles on rheological properties of mud drilling. Int J Nanosci Nanotechnol 8(3): 171-174.

18. Liu P, Mu Z, Wang C, Wang Y (2017) Experimental study of rheological properties and oil displacement efficiency in oilfields for a synthetic hydrophobically modified polymer. Scientific Reports 7: 8791.

19. Wang S, Li A (2018) Effect of water content and temperature on the rheological behavior of Caoqiao heavy oil. Petroleum science and technology 36(11): 739-743.

20. Saboori R, Sabbaghi S, Mowla D, Soltani A (2012) Decreasing of water loss and mud cake thickness by CMC nanoparticles in mud drilling. Int ] Nano Dimen 3(2): 101-104. 
Creative Commons Attribution 4.0 International License

For possible submissions Click Here

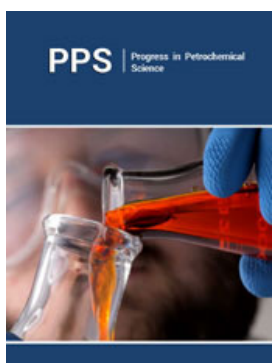

\section{Progress in Petrochemical Science}

\section{Benefits of Publishing with us}

- High-level peer review and editorial services

- Freely accessible online immediately upon publication

- Authors retain the copyright to their work

- Licensing it under a Creative Commons license

- Visibility through different online platforms 